\title{
14. LA CONSTITUCIÓN ECONÓMICA
}

\author{
MARTÍN BASSOLS COMA \\ Catedrático de Derecho Administrativo \\ "San Pablo" CEU. Madrid
}


SUMARIO

INTRODUCCIÓN: Planteamiento general Y MÉTOdO EXPOSITIVO.-l. EL DERECHO DE PROPIEDAD Y LA EXPROPIACIÓN FORZOSA. ESPECIAL REFERENCIA AL DERECHO A LA VIVIENDA (Art. 33 y 47).-III. LA LIBERTAD DE EMPRESA (Art. 38).-III. INICIATIVA PÚBLICA EN LA ECONOMIA Y RESERVAS AL SECTOR PÚBLICO (Art. 128). -IV. PLANIFICACIÓN DE LA ACTIVIDAD ECONÓMICA GENERAL (Art. 131). 


\section{LA CONSTITUCIÓN ECONÓMICA}

POR

MARTÍN BASSOLS COMA

Catedrático de Derecho Administrativo

"San Pablo" CEU. Madrid

\section{INTRODUCCIÓN: PLANTEAMIENTO GENERAL Y MÉTODO EXPOSITIVO}

El análisis de los temas relacionados con la Constitución económica en el marco de la Constitución española de 1978 en orden a los objetivos que pretende este Congreso sobre "La Reforma Constitucional» - valoración de la funcionalidad del texto constitucional durante estos trece años de vigencia y la presentación de eventuales propuestas de reforma redactadas con la forma $y$ el estilo normativo requieren de la formulación de una serie de consideraciones de orden general y metodológico.

A) En primer lugar, pese al acotamiento temático que se nos ha asignado, es manifiesta la abundancia de preceptos de naturaleza económica en el texto constitucional y su absoluta falta de sistemática. Las materias de índole económica están dispersas por todo el articulado, desde el preámbulo a, prácticamente, el último artículo. Este dato impone una selección previa de los capítulos o materias que se consideran que integran el núcleo fundamental de dicha Constitución económica, selección que, obviamente, siempre responderá a criterios subjetivos.

B) Dentro de las materias que se pueden considerar como básicas o esenciales - art. 33, 36, 128, 131 y los llamados Principios de Rectores de la política social y económica-cabe apreciar que sus respectivos textos 
están redactados con un amplio propósito de flexibilidad y de indeterminación en cuanto pretenden fundamentalmente una Constitución económica abierta, en ningún caso predictiva de modelos económicos fijos. Esta formulación, fruto del compromiso constituyente, ha dado excelentes resultados en el orden político y en el del gobierno de la economía española que durante estos trece años ha pasado por duras pruebas de crisis $y$ que, afortunadamente, inició a partir de 1985 una importante recuperación. Paralelamente, en el terreno de las ideas económicas el cambio de mentalidad experimentado en orden a la política económica ha sido notable en relación con las vigentes en el momento de aprobarse la Constitución, habiendo podido facilitar el texto constitucional apoyo a este nuevo panorama sin necesidad de reformar la Constitución.

Lógicamente, esta flexibilidad ideológica tiene su repercusión y coste en el ámbito técnico-jurídico, por cuanto la interpretación y aplicación de sus preceptos abre profundos interrogantes y un semillero de problemas de auténtico rango constitucional que va resolviendo el Tribunal Constitucional progresivamente. Por ello, entendemos que ésta no es la ocasión de hacer una referencia a esta problemática interpretativa e intentar plasmarla en el texto constitucional a modo de una revisión puntual de sus lagunas o contradicciones de signo esencialmente hermeneútico. Con ser importantes estas cuestiones $-y$ a las que en todo caso hay que hacer una sumaria referencia al comentario inicial de cada artículo- parece que el genuino sentido del Congreso sea el de valorar y aportar ideas innovadoras y operativas de nuevo cuño para el horizonte del constitucionalismo económico, todo ello, con independencia de que si en un punto concreto pueda enmendarse una corrección o concordancia técnica importante se pueda señalar o apunta.

C) A mayor abundamiento, debe destacarse que los preceptos de carácter económico e incluso la misma interpretación de unos mismos conceptos, revisten un claro dualismo, según se interpreten en el marco de la economía en general (visión horizontal) o en función de la distribución territorial del poder en favor de las Comunidades Autónomas (visión vertical). Por razones de asignación temática, prescindiremos en el presente caso de las referencias al sistema territorial de distribución de competencias económicas.

D) Por último, como una prueba más de la flexibilidad de nuestra Constitución económica basta considerar que ha permitido -al menos hasta el momento- la incorporación a la CEE en 1985 sin necesidad de revisar la Constitución. Ello pone de relieve, paralelamente, cómo nuestros constituyentes elaboraron el diseño económico constitucional pensando fundamentalmente en su encaje en la Constitución económica de la CEE. 
Esta situación contrasta con el caso de Portugal que, a través de las Reformas Constitucionales de 1982 y 1989, ha procedido prácticamente a la revisión ideológica, conceptual y técnica de los preceptos de su Constitución de carácter económico para compatibilizarla con el orden económico de la CEE.

La incorporación a la CEE en 1985, se complementó en 1986 con la firma del Acta Única y el ingreso en 1989 en el Sistema Monetario Europeo (proceso al que habrá que añadir los acuerdos de Maastricht). Estos acontecimientos tienen una doble dimensión valorativa. Por una parte, suponen un cambio significativo en el componente de la Constitución económica en sentido material al pasar a formar parte nuestro país del espacio económico intracomunitario. Por otra, en el plano jurídico-constitucional, la conexión entre la Constitución económica de la CEE y la Constitución económica española, y sus relaciones de coordinación y colaboración. Desde esta perspectiva son evidentes las limitaciones que se ofrecen a la revisión de nuestro texto constitucional en materia económica, pues cualquier innovación que en este orden se plantee deberá ser compatible con los objetivos y procedimientos de la CEE. En puridad puede darse la paradoja de que los nuevos contenidos de la CEE determinen la revisión de la parte institucional-política de nuestro texto constitucional, pudiendo permanecer inalterada la parte referida a la materia económica, interpretadas a los objetivos de la CEE.

E) Las anteriores observaciones condicionan evidentemente el alcance de nuestra intervención. Por todo ello, en cada uno de los artículos comentados haremos una breve referencia a la funcionalidad de los preceptos en el orden político y en el de la interpretación técnico-jurídico, para dar paso, en su caso, a las posibles modificaciones innovadoras del texto.

\section{EL DERECHO DE PROPIEDAD Y LA EXPROPIACIÓN FORZOSA. ESPECIAL REFERENCIA AL DERECHO A LA VIVIENDA (Arts. 33 y 47 )}

1. La regulación del derecho de propiedad privada contenido en el artículo 33 de la Constitución y su vinculación a la función social ha dado un amplio juego en la etapa postconstitucional, especialmente en lo que se refiere a la propiedad agraria (en especial en relación con la Ley de Reforma Agraria de Andalucía que ha dado lugar a la importante Sentencia del Tribunal Constitucional de 20 de marzo de 1987) y la propiedad del 
suelo LLey de 8/1990 de 25 de julio sobre la Reforma del Régimen Urbanístico y Valoraciones del Suelo). Ambos textos representan las innovaciones más trascendentales sobre el régimen de la propiedad, hasta el punto que la Sentencia de 20 de marzo de 1987 del Tribunal Constitucional haya especificado que udebe rechazarse de entrada, por infundada, la pretensión de los recurrentes de identificar el contenido esencial de la misma, atendiendo exclusivamente a lo que el Código Civil, declinado el siglo XIX, dispuso con carácter general en su art. 348, porque tal pretensión no tiene para nada en cuenta las modulaciones y cambios que ha venido sufriendo desde entonces el instituto de la propiedad privada, en general y de la propiedad agraria en particular».

Desde el punto de vista de la Constitución económica, el art. 33 es, por lo tanto, esencial, si bien la generalidad de su formulación, dota a cada una de sus concreciones de un estatuto singular (propiedad rústica, urbana, industrial, intelectual, etc.) que a veces queda con cierta indefinición cuando se concreta en la vertiente de la propiedad de la propia empresa y de las participaciones societarias en la misma, aspectos que deben complementarse o tratarse al estudiar el art. 38 sobre la iniciativa económica y la libertad de empresa.

2. El problema más delicado que plantea el art. 33 radica en su apartado 3 que hace referencia a la expropiación forzosa en la que el concepto genérico de propiedad tiene un importante papel en cuanto sirve de garantía de la indemnización. Ahora bien, la eliminación del carácter previo a la indemnización -por razones que ampliamente se expusieron en el debate constituyente,- no ha dejado de suscitar dificultades de interpretación cuando se han presentado los fenómenos de las llamadas expropiaciones legislativas o bien las declaraciones legislativas de demanialidad de tipos de propiedad que anteriormente eran privados (Leyes de Aguas de 1985 y de Costas de 1988). Por ello, parece necesario que se reconozca el fenómeno de las expropiaciones legislativas y se prevea la fijación de un plazo límite para el abono de la indemnización, que si bien ha perdido el carácter de previo, no por ello su pago puede sufrir una demora excesiva.

Paralelamente, a estas modificaciones debería especificarse en el mismo precepto que en ningún caso podrán computarse - al menos para la propiedad inmueble - o tenerse en cuenta plusvalías derivadas de la propia obra o servicio determinantes de la expropiación o generadas por la Comunidad.

A tal efecto, podría proponerse una redacción del apartado 3 del art. 33 del siguiente tenor: 
"Nadie podrá ser privado de sus bienes y derechos sino en virtud de una Ley o por causa justificada de utilidad o interés social, mediante la correspondiente indemnización y de conformidad con lo dispuesto en las leyes. La indemnización deberá abonarse en el plazo máximo de dos años desde la iniciación del expediente de fijación de aquélla y en ningún caso podrán tenerse en cuenta en la valoración del bien expropiado plusvalías generadas por planes o actuaciones administrativas".

3. En directa relación con el tema de las plusvalías y, en concreto, con las plusvalías urbanística debería tenerse en cuenta el art. 47 sobre el llamado derecho a la vivienda, precepto que anunciado en forma de derecho - cualquiera que sea el alcance que del art. 53 de la Constitución se derive - suscita unas expectativas en la sociedad que no se corresponde con una acción posible y de cobertura universal por parte de los poderes públicos. Por otra parte, este artículo sólo anuncia acciones de los poderes públicos sobre el suelo, sin aludir acciones en materia de arrendamientos, beneficios para la adquisición de viviendas públicas, rehabilitación de las mismas, etc. En alguna medida debería contenerse un catálogo de acciones concretas a seguir por los poderes públicos, con una cláusula final genérica.

\section{LA LIBERTAD DE EMPRESA (Art. 38)}

1. El reconocimiento de la Libertad de Empresa (art. 38), como un derecho o libertad constitucionalmente garantizado con el alcance que le otorga el art. 53.1 del texto constitucional, adquiere un carácter emblemático en el conjunto de nuestra constitución económica al modularse en función de un parámetro - "en el marco de la economía de mercado"- que no es propiamente un concepto técnico-jurídico, sino que nos remite a consideraciones económicas, de sociología económica, o de ideología político-económica con un claro propósito de condicionar e influir en el modelo global del sistema económico.

Como ya se advirtió, desde un primer momento, el marco o continente - la Economía de Mercado- estaba destinado a tener más relevancia y protagonismo que el contenido propiamente dicho: la libertad de Empresa. Aun a pesar de la ambigüedad del concepto y de sus disfunciones con lo cual su aportación a la determinación del contenido esencial de la libertad de empresa es relativamente escaso, lo cierto es que la referencia constitucional a la Economía de Mercado ha tenido un carácter simbólico y de paradigma para el sistema económico español en el período postcons- 
titucional inmediato: en cuanto se han propiciado liberalizaciones o desregulaciones de sectores fuertemente intervenidos, $y$, en especial, ha favorecido el ingreso en la CEE.

Precisamente a raíz de la incorporación a la CEE se han destacado dos aspectos de la "economía de mercado" que si podian considerarse implícitamente subsumidas en esta fórmula, no lucen en el texto constitucional $y$, por su eficacia caracterizadora del contenido esencial de la libertad de empresa, merecerían algún tipo de alusión en el art. 38. Nos referimos en concreto a las recientes leyes 16/1989 de 17 de julio de Defensa de la Competencia y la Ley 3/1991 de 10 de enero sobre Competencia Desleal. En ambos textos legales - auténtico derecho de organización del Mercado en general- se contienen en el articulado y en sus preámbulos referencias a la trascendencia de la economía de mercado. Así, en el preámbulo de la primera se afirma «la competencia, como principio rector de toda economía de mercado, representa un elemento consustancial con el modelo de organización económica de nuestra Sociedad, y constituye en el plano de las libertades individuales, la primera y más importante forma en que se manifiesta el ejercicio de la libertad de empresan. La existencia de una legislación comunitaria al respecto sobre la materia justifican su recepción en el texto constitucional como complemento al art. 38, en cuanto coadyuva a la determinación del contenido esencial del derecho a la libre empresa y puede ayudar a descargar su texto de la suma de implicaciones $y$ cláusulas condicionantes que se mantienen en la redacción vigente.

2. En efecto, en el art. $\mathbf{3 8}$ cabe distinguir dos aspectos: el núcleo fundamental del derecho - la libertad de empresa - y la normativa indicativa o directiva de un principio orientativo o programático dirigido a los poderes públicos (garantizarán y protegerán su ejercicio...).

Respecto al núcleo fundamental del derecho, su enunciación como "libertad de empresa" no deja de plantear importantes temas dogmáticos e interpretativos, por cuanto la referencia a la empresa en sí misma considerada, remite una serie de cuestiones que inmediatamente colisionan con otros derechos o aspectos - forma jurídica de la organización empresarial, titularidad jurídica patrimonial de la misma, modelo jurídico-social de toma de decisiones en el interior de la organización, etc.- cuando en realidad lo que se pretende con el reconocimiento del derecho es precisamente destacar la libre iniciativa empresarial o económica en el conjunto del sistema económico, con independencia de las formas de su organización y titularidades. Es precisamente, el despliegue de esta capacidad o iniciativa la que justifica su reconocimiento como un derecho público subjetivo, digno de protección constitucional. De ahi que propongamos una corrección conceptual de este precepto que ayude a clarificarlo y puedan descartarse 
problemáticas ajenas -como la experiencia ha evidenciado- que pretenden ampararse en su indeterminación.

Paralelamente, en la faceta del art. 38 que remite a conceptos directivos determinantes de la garantía y protección se alude a la expresión «de acuerdo con las exigencias de la economía general y, en su caso, de la planificación». Esta formulación alternativa - globalidad de la economía frente a planificación - tiene sus claves interpretativas en el conjunto del texto constitucional con especial referencia al art. 131 del mismo y su apelación a una opción planificadora. Con independencia de lo que más adelante se dirá sobre la planificación en general (art. 131), lo cierto es que no puede interpretarse el "en su caso" del art. 38 como dos bloques o mecanismos contrapuestos y no comunicables, de tal suerte de que sólo puede apelarse a la planificación cuando se ha canalizado a través del art. 131. La experiencia postconstitucional ha evidenciado que sin una planificación general y formal de la economía (art. 131), han existido planificaciones sectoriales (energética, hidrológica, investigación científica...) y de detalle (reindustrialización y reconversión industrial) que han sido plenamente admitidas, incluso por la jurisprudencia constitucional (Vid STC 29/1986 de 20 de febrero sobre Planes de Reconversión y reindustrialización industrial).

3. Por todo lo expuesto, podría formularse una revisión del art. 38 en los siguientes términos:

"Se reconoce el derecho a la libre iniciativa económica privada. La ley regulará su ejercicio en los distintos sectores, de acuerdo con exigencias de la economía general $y$, en su caso, de la planificación.

Los poderes públicos garantizan y protegen el ejercicio de la libertad de empresa, inherente a la iniciativa económica privada, y la defensa de la productividad en el marco de la libre competencia económica y concurrencia leal».

\section{INICIATIVA PÚBLICA EN LA ECONOMÍA Y RESERVAS AL SECTOR PÚBLICO (Art. 128)}

1. En este importante y decisivo precepto de la Constitución económica están concentradas las claves de la actuación del sector público en las actividades económicas. Partiendo de una declaración general sobre la subordinación de la riqueza del país al interés general, se regula: 1) La iniciativa pública en la actividad económica en concurrencia con la privada. 
2) El procedimiento para la reserva al sector público -es decir, de sustracción a la iniciativa privada de su libertad de acceso y, eventualmente de gestión, de determinadas actividades, calificadas de recursos o servicios esenciales. La gestión de dichos servicios o recursos no necesariamente tendrá que ser pública, sino que podrá concederse a la iniciativa privada (concesión administrativa) o por vías mixtas (sociedad mixta, gestión interesada, etc.). 3) Finalmente, se prevé la posibilidad de intervención de empresas cuando asi lo exigiese el interés general. Lógicamente estas empresas hay que presumir que son las privadas o aquellas sobre las que las Administraciones no pueden ejercer su control o dirección patrimonial (empresas mixtas en que el sector público no disponga de la mayoria), puesto que en caso contrario bastaría ejercer las simples facultades de control administrativo.

2. Desde el punto de vista técnico-jurídico, la problemática de este precepto es densa, por los abundantes problemas que suscita su interpretación a un ámbito tan extenso y problemático como es el del sector público económico en sí mismo considerado y, en relación con el ámbito específico de los sectores estatal, autonómico y local. En síntesis, las principales cuestiones implicadas son las siguientes: a) alcance de la expresión "mediante ley", frente a las actuaciones ordinarias sometidas al principio de legalidad (en base o de acuerdo con la ley). $b$ ) Interpretación que deba darse a los conceptos de recursos o servicios esenciales objeto de reserva y conveniencia o no que la Constitución detalle o enumere alguno de ellos. c) Si las reservas pueden ser originadas o derivativas, y en este último caso, si la medida de reserva debe comportar o no indemnización por constituir una expropiación legislativa. d) Régimen de la Empresa Pública (concurrencial o de servicio público) que emerge de la aplicación de este precepto, así como de su régimen de control y, eventual Estatuto de la Empresa pública.

3. Por densos que puedan parecer los temas técnico-jurídicos planteados, lo decisivo de este precepto en la filosofía constitucional que encierra en orden a asentar uno de los principios básicos de la Constitución económica: la coexistencia pacífica del sector público y privado en el marco de la economía, pruritos de distribución apriorística de campos o apelaciones al principio de subsidiaridad. Es ésta una directriz que se desprende muy claramente en los debates constituyentes y que incluso ha sido constatada en una Sentencia del Tribunal Supremo de 14 de febrero de 1990 donde se dice que "el artículo 128.2 CE reconoce la iniciativa pública en la actividad económica con lo que se proclama en nuestro sistema constitucional la coexistencia de dos sectores, el privado y el público, que constituye lo que se ha dado en llamar un sistema de economía mixta, apartándose así nuestra Constitución del orden político anterior en el que primaba el principio de subsidiaridad". 
Esta falta de dogmatismo $y$ de reparto de campos previos ha permitido que en período postconstitucional el sector público evolucionara en atención a las exigencias de la economía española y del gasto público, reorientando algunas de sus tendencias.

Precisamente, en función de esta reorientación flexible han aparecido fenómenos y actuaciones nuevas que no están contempladas en el texto constitucional, tales como las reprivatizaciones (bajo denominaciones de reestructuración, acceso del capital extranjero, ampliación base accionarial, simple enajenación de activos) o liberalización o desregulación de sectores previamente reservados al Estado. Estos fenómenos precisan de un previo reconocimiento constitucional, en sus grandes líneas, a fin de evitar disfunciones que ya se han dado en la experiencia práctica. Análogamente, la gestión empresarial del sector público se ve afectada en orden a criterios de economicidad y competitividad, derivadas de las intensas directrices que en este orden proceden de nuestra integración en la CEE.

3. A la vista de estas consideraciones podría sugerirse la siguiente redacción del art. 128:

«1. Los recursos y bienes económicos y en general toda la riqueza del pais en sus distintas formas y sea cual sea su titularidad están subordinados al interés general.

2. Se reconoce la iniciativa pública en la actividad económica. La actuación del sector público económico responderá a criterio de eficiencia y economicidad.

3. Mediante Ley se podrá reservar al sector público recursos o servicios esenciales, especialmente en caso de monopolio y asimismo acordar la intervención de empresas cuando así lo exigiere el interés general.

4. Por Ley podrán regularse los requisitos y procedimientos para la privatización de empresas públicas, así como de actividades económicas que estuvieren reservadas al sector público».

Como puede observarse, las modificaciones introducidas son mínimas. Por una parte, en el apartado 1 se refuerza y especifica la subordinación al interés general, no sólo de la riqueza (término muy poco técnico e impreciso), sino de los recursos y bienes económicos, como elementos materiales del sistema económico productivo.

En el párrafo 2, se formulan unas mínimas indicaciones sobre la actuación del sector público empresarial, previstas por la CEE. 
Se añade un párrafo final sobre la privatización de empresas públicas y actividades anteriormente reservadas, a fin de que se constitucionalice esta posibilidad. Se establece la matización de que es la Ley y no mediante Ley, por cuanto ello permite una mayor flexibilidad para que los diferentes sectores de actividad prevean los motivos y procedimientos de estas operaciones.

\section{PLANIFICACIÓN DE LA ACTIVIDAD ECONÓMICA GENERAL (Art. 131)}

1. El artículo 131 es uno de los que presenta una interpretación más compleja de nuestro texto constitucional, tanto en lo que afecta a la exégesis de sus densas proposiciones normativas que encierra, como por el contraste que se ha evidenciado en la fase postconstitucional por parte de los poderes públicos entre su invocación funcional y legitimadora, y su resistencia a su aplicabilidad y desarrollo operativo. En efecto, si se repasa la problemática que encierra este artículo con la realidad postconstitucional se podrá observar el siguiente cuadro:

a) La planificación en cuanto instrumento operativo general por parte del Estado ha sido prácticamente abandonado en aras a la actuación presupuestaria anual, si bien existen órganos administrativos de Planificación en el Ministerio de Economía y Hacienda y en alguna medida los estudios de estos órganos orientan la actividad presupuestaria o, al menos, son tenidos en cuenta por el ejecutivo al elaborar los presupuestos.

b) La inactuación de la planificación económica general contrasta con su constante y reiterada invocación, al amparo del art. 149.1.13 de la $C E$, por parte del Estado para justificar sus competencias en el orden económico en relación con las posibles competencias económicas de las Comunidades Autónomas. El contraste entre uplanificar la actividad económica general» del art. 131 y "planificación general de la actividad económica» del art. 149.1.13 ha permitido un uso alternativo de estos conceptos y ha convertido a la planificación económica de instrumento operativo global en sinónimo de competencia estatal para la ordenación económica. Este dato es perfectamente visible en los textos de los Estatutos de Autonomía, en las leyes ordinarias y en las propias cláusulas de reserva que el Estado impone a las Comunidades Autónomas asumen en sus leyes o actuaciones. 
Pese a este efecto interpretativo, la experiencia -especialmente a partir de la incorporación a la CEE- pone de relieve la aparición de un nuevo tipo de planificación o programación de las Comunidades Autónomas (programas de desarrollo regional) que, no obstante, son coordinados por el Estado, a efectos de su presentación ante los organismos de la CEE al margen del art. 131 de la Constitución.

c) El art. 131 en cuanto prevé un sistema de representación de las fuerzas productivas y de las Comunidades Autónomas a través de un Consejo que ni siquiera recibe denominación alguna, ha sido objeto de cuestionamiento y de enfrentamiento constante en las Cortes Generales entre los Gobiernos que se han sucedido desde 1978 hasta la actualidad y determinadas fuerzas políticas partidarias de la planificación económica.

En este orden de cuestiones es significativo que del primer debate sobre el tema se suscitó - Programa a Medio Plazo para la Economía Española (PEG), desarrollado en el Congreso de los Diputados en 1979,surgió precisamente la iniciativa de denominar a este Consejo, como Económico y Social a efectos de que los urepresentantes sindicales y empresariales debatan los problemas globales y sectoriales que incidan directamente en las relaciones industriales". Desde esta fecha hasta la aprobación de la Ley de 17 de junio de 1991 sobre creación del Consejo Económico y Social, han sido múltiples las proposiciones de Ley sobre este Consejo y los debates parlamentarios sobre el mismo. Es significativo respecto a esta ley: 1) Que su fundamento constitucional se apoya explícitamente en el derecho a la participación reconocido en diverso preceptos y no específicamente en el art. 131, no reconociéndose al propio tiempo como un desarrollo de dicho artículo. Significativamente, no se reconoce el derecho de las Comunidades Autónomas a participar en el mismo Consejo, por lo cual el tema de la articulación Estado-Comunidades Autónomas en materia de planificación sigue pendiente, 2) Que en el texto de la Ley no se hace alusión en ningún momento al tema de la planificación económica $y$, en concreto, se excluye del informe obligatorio del Consejo al Anteproyecto de Ley de Presupuestos del Estado.

d) Por último, el tema de la planificación de la actividad económica general ideológicamente remite a la polarización: economía de mercado-economía planificada, son la secuela de los problemas de los efectos indicativos o vinculantes para la iniciativa privada o para el sector público.

Sobre estas cuestiones ideológicas, como hemos apuntado, el texto constitucional no quiso pronunciarse, omisión que - pese a debatirse en la elaboración del texto- forma parte del acto implícito sobre el que se asienta la Constitución económica. De otro lado, gran parte de este debate 
responde a un modelo sobre la planificación indicativa al estilo francés de difícil trasplante a otros países. Lo cierto es que se han elaborado planes sectoriales $y$ de detalle (reindustrialización), no planteándose excesivas cuestiones sobre la interpretación del alcance de las medidas de planificación sectorial o de detalle por parte del Tribunal Constitucional y de los Tribunales Ordinarios.

2. A la vista de la problemática expuesta, pueden plantearse algunas de las siguientes opciones sobre este precepto: 1) eliminarlo por inútil, 2) modificar su redacción, destacando exclusivamente sus aspectos funcionales y de articulaciones no rígida de los protagonistas de la planificación: Estado y Comunidades Autónomas, eliminando los problemas de la participación de sindicatos y organizaciones empresariales que ya han alcanzado su articulación por la vía del Consejo Económico y Social, y 3) replantearse íntegramente su funcionalidad en el marco de un precepto que englobe la planificación como título constitucional de competencia del Estado con relación a las Comunidades Autónomas, disciplinando todo el entramado de relaciones, con eventual participación del Senado en cuanto Cámara territorial en la elaboración y aprobación de los Planes.

Por nuestra parte, nos inclinamos por la segunda de las alternativas suscitadas a los específicos efectos de esta Ponencia, puesto que la tercera de las alternativas exigiría introducirnos en temas - régimen de Comunidades Autónomas y Senado-que desarrollan otros autores. Por otra parte la supresión simple y pura del artículo 131 parece excesiva, puesto que en un futuro el tema de la planificación puede volver a cobrar actualidad.

A tal efecto, podría proponerse una nueva redacción del art. 131 del siguiente tenor:

"1. El Gobierno, previa consulta a las Comunidades Autónomas podrá promover la elaboración de planes generales de desarrollo económico para atender a las necesidades colectivas, equilibrar, ordenar, y armonizar el territorio, el desarrollo regional y sectorial, así como estimular el crecimiento de la renta y de la riqueza y su más justa distribución. Corresponde al Congreso de los Diputados aprobar las grandes opciones correspondientes a cada plan y las propuestas de resolución que se deriven de su debate.

2. La coordinación entre los Planes o Programas de desarrollo regional de las Comunidades Autónomas y la planificación económica general del Estado se llevará a cabo a través del Senado". 